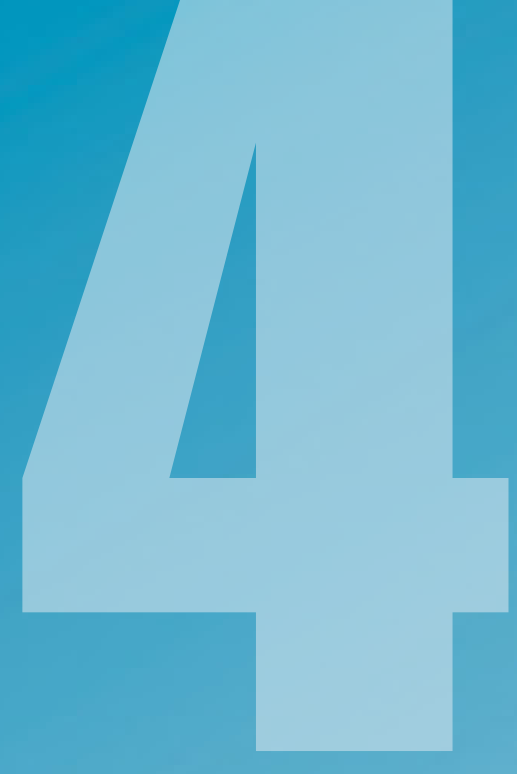

ÁMBITOS

REVISTA

INTERNACIONAL

DE COMUNICACIÓN

$N^{\circ} 46$

EDICIÓN OTOÑO

2019

ISSN: 1139-1979

E-ISSN: 1988-5733

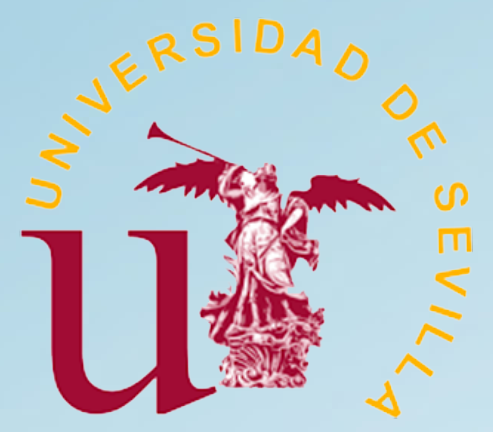




\section{ÍNDICE}

MONOGRAFICOS MONOGRAPHS

Presentación Monográfico. Comunicación emergente. Experiencias para el cambio social

Dra. Nereida López Vidales

Los formatos de televisión más consumidos por los jóvenes: telerrealidad y empoderamiento de la audiencia

Most consumed televisión formats by young people: real TV and the empowerment of the audience Nereida López Vidales, Leire Gómez Rubio, Elena Medina de la Viña

Nuevas herramientas, viejas costumbres El Contenido Generado por los Usuarios sobre el cambio climático en YouTube

New tools, old habits User Generated Content about climate change on YouTube

David Vicente Torrico

Tratamiento periodístico de personas LGTBIQ+ refugiadas: estudio de caso sobre Pride Barcelona 2018

Journalistic treatment of LGTBIQ+ refugees: case study on Pride Barcelona 2018

Hadriel Theodoro, Amparo Huertas Bailén

Tiempo Muerto, estudio de caso de un proyecto transmediático para la consecución de competencias universitarias

Tiempo Muerto, case study of a transmediatic project for the achievement of university competences Jose L. Carreño Villada, Miguel Ángel Díaz Monsalvo

Los universitarios millennials: uso de redes sociales y relación con las marcas

University Millennials: use of social media and engage with brands

Pedro Pablo Marín Dueñas, Esther Simancas González

Ali Ferzat: De la caricatura comunicativa en papel a la caricatura activista en los medios digitales

Ali Ferzat: From political cartoons in papers to political cartoons in digital media

Salud Adelaida Flores Borjabad

Direito à informação e literacia midiática: Reflexões sobre a questão do acesso

Right to information and media literacy: Reflections on the question of acce

Christiane Delmondes Versuti 
Eficacia de los influencers como recurso publicitario en la estrategia de los anunciantes locales Efficacy of influencers as an advertising resource in the strategy of local advertisers

Isabel Iniesta-Alemán

As redes sociais como ferramenta de marketing em instituições de ensino superior no Brasil Social networks as a marketing tool in higher education institutions in Brazil

Alcino Ricoy JR, Rogério Eduardo Rodrigues Bazi

Estudio sobre la conceptualización y el tratamiento informativo de la violencia de género en la prensa digital cubana

Study about the conceptualization and information treatment of gender violence in the Cuban digital press

Regla Ismaray Cabreja Piedra, Karina Escalona Peña

\section{ARTÍCULOS ARTICLES}

Uso de Twitter durante los debates electorales televisados en los comicios andaluces de 2018 The use of Twitter during the televised electoral debates in the 2018 Andalusian elections Julia Fontenla Pedreira, Erika Conde Vázquez, Carmen Máiz Bar

Quem averigua as notícias, os algoritmos ou jornalistas? A lógica crítica de C. S.

Peirce como processo de identificação de uma Fake News

Who checks the news, algorithms or journalists? The critical logic of C. S. Peirce as a

process for identifying a Fake News

Adelino de Castro Oliveira Simões Gala, Vania Baldi, Universidad de Aveiro

\section{RESEÑAS REVIEWS}

Nuevo ecosistema comunicativo digital: El consumidor

Juan Carlos Figuereo Benítez

Corpus toponímic de Beniarrés

Bianca Sánchez-Gutiérrez

The Future Computed. La inteligencia artificial y su papel en la sociedad y Pulsa actualizar. La aventura de redescubrir el alma de Microsoft y concebir un futuro mejor para todos 


\title{
Direito à informação e literacia midiática: Reflexões sobre a questão do acesso ${ }^{1}$
}

\author{
Right to information and media literacy: \\ Reflections on the question of access
}

\author{
Christiane Delmondes Versuti, Universidade Estadual Paulista Júlio de Mesquita \\ Filho, UNESP Bauru, Av. Eng. Luís Edmundo Carrijo Coube, 14-01 - Nucleo Res. \\ Pres. Geisel, Bauru - SP, 17033-360 \\ christianedversuti@hotmail.com | Orcid: http://orcid.org/0000-0002-9516-7211
}

DOI: http://dx.doi.org/10.12795/Ambitos.2019.i46.08

\begin{abstract}
Resumo
Este trabalho tem como objetivo apresentar o conceito de literacia midiática e também as principais características de um regime de direito à informação, apontados por Mendel (2009) em sua obra "Liberdade de informação: um estudo de direito comparado". Após essa contextualização, serão tecidas relações de tais características com as premissas da literacia midiática, principalmente no que se refere à questão do acesso à informação. Para tal, foi realizado levantamento bibliográfico sobre o conceito de Lieteracia Midiática e acerda dos princípios de um regime de acesso à informação. O conceito de literacia midiática, de forma geral, refere-se à capacidade de acesso e utilização dos media; capacidade de avaliar criticamente a informação; e fazer uso criativo dos media, para comunicar e participar ativamente como cidadão, promovendo a garantia de direitos e deveres. Já os Princípios de um Regime de Direito à Informação apontados por Mendel (2009) são: 1) Divulgação Máxima; 2) Obrigação de Publicar; 3) Promoção de um Governo Aberto; 4) Abrangência Limitada das Exceções; 5) Procedimentos que Facilitam o Acesso; 6) Custos; 7) Reuniões Abertas; 8) Precedência da Divulgação; 9)
\end{abstract}

Forma de citar:

Delmondes Versuti, C. (2019). Direito à informação e literacia midiática:Reflexões sobre a questão do acesso. Ámbitos.

Revista Internacional de Comunicación 46, pp. 133-148. doi: 10.12795/Ambitos.2019.i46.08 
Proteção para os Denunciantes. Parte-se da ideia de que, se as características do regime de direito à informação existirem de fato, podem potencializar de maneira substancial o processo de literacia midiática.

\section{Abstract}

This paper aims to present the concept of media literacy and also the main characteristics of a regime of right to information, pointed out by Mendel (2009) in his work "Freedom of information: a study of comparative law." After this contextualization, relations of such characteristics will be woven with the premises of media literacy, especially with regard to the issue of access to information. The concept of Media Literacy, in general, refers to the capacity of access and use of the media; ability to critically evaluate information; and make creative use of the media, to communicate and actively participate as a citizen, promoting the guarantee of rights and duties. The Principles of a Right to Information System pointed out by Mendel (2009) are: 1) Maximum Disclosure; 2) Obligation to Publish; 3) Promotion of an Open Government; 4) Limited scope of exceptions; 5) Procedures that Facilitate Access; 6) Costs; 7) Open Meetings; 8) Precedence of Divulgation; 9) Protection for Denunciators. It starts from the idea that, if characteristics of the right to information regime do exist, they can substantially enhance the process of media literacy. To this end, a bibliographical survey was carried out on the principles of a regime of access to information and media literacy.

Palavras-chave: Acesso à informação; Direito à informação; Direito internacional; Literacia Midiática; Cidadania.

Keywords: Access to information; Right to information; International right; Media literacy; Citizenship.

\section{INTRODUÇÃO}

Neste artigo pretende-se apresentar as definições de Literacia Midiática colocadas por autores como Perez Tornero \& Tapio Varis (2010), Bévort \& Belloni (2009); e Andrelo \& Bighetti (2015) e tecer relações com o direito de acesso à informação e com as principais características de um regime de direito à informação, apresentadas por Mendel (2009) no livro "Liberdade de informação: um estudo de direito comparado", no qual traz diversas referências internacionais sobre o direito à informação. A metodología utilizada para alcançar os objetivos do artigo foi o levantamento bibliográfio sobre o conceito de literacia midiática e acerca das características de um regime de direito à infomação.

Partindo para o conceito de literacia midiática, de forma geral, refere-se ao saber lidar com a presença das mídias na vida cotidiana; ter a possibilidade de acesso às informa- 
ções; desenvolver competências de análise crítica dessas informações; e por fim, apropriar-se dessas informações e dos meios de comunicação para exercer uma participação cidadã, promovendo a garantia de direitos e deveres.

Após a contextualização sobre literacia midiática, serão apresentados os princípios de um regime de direito à comunicação, apontados por Mendel (2009) após analisar diversos textos internacionais sobre leis relativas ao direito à informação. Esses princípios são: 1) Divulgação Máxima; 2) Obrigação de Publicar; 3) Promoção de um Governo Aberto; 4) Abrangência Limitada das Exceções; 5) Procedimentos que Facilitam o Acesso; 6) Custos; 7) Reuniões Abertas; 8) Precedência da Divulgação; 9) Proteção para os Denunciantes.

Ao longo do artigo, serão feitas articulações entre os princípios do direito à informação e literacia midiática, com foco na etapa do acesso à informação, apontando para que a consolidação desses princípios tragam importantes contribuições à cidadania, que é um dos objetivos da literacia midiática.

\subsection{O conceiteo de Literacia Midiática}

O conceito de literacia midiática, ou media literacy, segundo Perez Tornero e Tapio Varis (2010:74), é composto pelos seguintes elementos: acesso; compreensão; e criação, se tratando da "capacidade de realmente usar os media, de os compreender criticamente e de ser capaz de avaliar informação e finalmente de criar, comunicar e participar".

Para os mesmos autores, a organização das competências de literacia mediática é dividida em três níveis: 1) Acesso à informação e aos media: no qual os autores distinguem o acesso físico aos media do acesso aos conteúdos; 2) Compreensão crítica: que se refere às capacidades e competências de ler, compreender e avaliar as informações; e 3) Competência comunicativa: terceiro e o mais elevado nível, incluindo competências de criação e produção de conteúdos, que podem ser difundidas através de diferentes formatos e plataformas. Neste último nível, assim como colocam os autores, estão incluídas competências de criação, expressão semiótica e social.

Já para a Comissão Europeia (2007), literacia midiática seria "a capacidade de aceder aos media, de compreender e avaliar de modo crítico os diferentes aspectos dos media e dos seus conteúdos e de criar comunicações em diversos contextos".

E de acordo com Bévort \& Belloni (2009), media literacy pode ser definida como a "formação para a compreensão crítica das mídias, mas também se reconhece o papel potencial das mídias na promoção da expressão criativa e da participação dos cidadãos, pondo em evidência as potencialidades democráticas dos dispositivos técnicos de mídia" (Bévort \& Belloni, 2009:1087). 
Elencadas tais noções sobre Literacia Midiática é possível retornar à questão de que apenas garantir o acesso à informação não basta, e por isso a importância e necessidade de uma formação que permita ao cidadão compreender as informações e utilizálas para refletir criticamente e atuar em seu dia a dia.

Assim, apontam Roseane Andrelo e Wanessa Bighetti, é preciso:

[...] oferecer aos cidadãos, em especial aos jovens, a formação necessária para saber analisar e utilizar as informações disponibilizadas pela mídia. Nesse sentido, é preciso que o cidadão, desde a infância e por meio da educação, seja capacitado a extrair da informação subsídios para pensar seu cotidiano de maneira crítica e agir de forma engajada e inclusiva. (Andrelo \& Bighettil, 2015:29).

Nesse sentido, além de educar o cidadão para extrair das informações subsídios para refletir sobre seu cotidiano, agir de forma crítica e engajada, também é importante educar o cidadão sobre seus direitos de expressão, de acesso à informação, de informar e ser informado, pois sabendo de tais direitos, amplia-se o acesso às informações necessárias para atuação cidadã. Aqui, vale retomar conceito de cidadania, que de acordo com Hack (2002:7), em suas múltiplas dimensões, pode ser entendido como a participação social para o conhecimento e exercício de direitos e deveres, e também para a proteção e garantia de tais direitos e deveres.

Assim, acredita-se que é preciso desenvolver nos cidadãos as competências para que sejam capazes de reconhecer em que momento determinada informação é necessária, e possuir conhecimento e habilidades de requerer, solicitar, localizar, avaliar e utilizá-la efetivamente na transformação de suas realidades, o que se relaciona intimamente ao direito à informação.

\section{PRINCÍPIOS DO DIREITO À COMUNICAÇÃO: REGIME DE DIREITO A INFORMAÇÃO E SUAS PRINCIPAIS CARACTERÍSTICAS:}

Como aponta Mendel (2009), o direito à informação e, em particular, o direito de acesso à informação que está de posse de órgãos públicos, constitui um direito humano fundamental, garantido pelo direito internacional que faz parte do direito à liberdade de expressão. $O$ entendimento mais abrangente do direito à informação pode ser obtido a partir de diversas declarações internacionais e decisões jurídicas referentes a tal direito.

De acordo com o autor, a garantia geral do direito à informação no direito internacional é favorável à divulgação de informações mantidas por órgãos públicos. Isso implica pressupor que "não apenas os Estados devem garantir o direito à informação, mas também que sistemas eficientes devem ser instaurados para efetivá-lo". 
Contudo, o direito a informação também admite certas restrições, como é apresentado no Artigo 19(3) do ICCPR (Pacto Internacional de Direitos Civis e Políticos), ratificado em 1976:

O exercício dos direitos previstos no parágrafo 2 deste artigo [o direito de liberdade de expressão] é revestido de deveres e responsabilidades especiais. Portanto, ele pode ficar sujeito a certas restrições, que deverão limitar-se àquelas previstas em lei e necessárias:

(a) Pelo respeito aos direitos ou reputações de outrem;

(b) Pela proteção da segurança nacional ou da ordem pública (order public), ou da saúde pública ou da moral. (ICCPR, 1976).

Assim, a restrição do direito à informação necessita de determinações e respaldo estabelecidos por lei, e as restrições que não apresentarem esse respaldo e não forem determinadas de forma convincente tornam-se ilegítimas. Essas leis de restrição também precisam ser formuladas de modo que o cidadão consiga compreendê-las e dessa forma saber como regular sua conduta e modo de agir.

Outro fator é que a restrição ao direito à informação precisa contemplar um dos objetivos legítimos presentes no Artigo 19(3) do ICCPR. Esses objetivos fazem parte de uma ampla lista, mas tornam ilegítimas restrições que visem metas como "impedir o constrangimento do governo", argumento que poderia ser facilmente manipulado para restringir o direito à informação nas mais diversas ocasiões em favor dos governantes corruptos, por exemplo.

Para uma compreensão mais abrangente do direito à informação e seus princípios gerais, uma série de padrões e declarações internacionais podem ser consultados, como o Relatório Anual de 2000, no qual o Relator Especial da ONU sobre Liberdade de Opinião e Expressão apresenta detalhadamente os padrões a serem observados pela legislação de direito a informação (Padrões da ONU).

Outro documento é a Recomendação de 2002 do Comitê de Ministros do Conselho da Europa (Recomendação do $\mathrm{CdE}$ ) que apresenta uma lista das metas legítimas que podem justificar exceções ao direito de acesso. Demais documentos importantes para o entendimento sobre o direito à informação são a Declaração Conjunta adotada pelo Relator Especial da ONU sobre Liberdade de Opinião e Expressão (2004); o Representante da OSCE para Liberdade da Mídia e o Relator Especial da OEA sobre Liberdade de Expressão em 2004 (Declaração Conjunta); os princípios adotados pelos ministros da Justiça da Commonwealth (Princípios da Commonwealth) de 1999; a Declaração de Princípios sobre Liberdade de Expressão na África (Declaração Africana) em 2002; a Declaração Interamericana de Princípios sobre Liberdade de Expressão (Declaração Interamericana) de 2000; a Convenção de Aarhus (2001); e a decisão da Corte Interamericana de Direitos Humanos, de setembro de 2006. 
Observando legislações de diferentes países e as diversas declarações e recomendações de conselhos internacionais é possível apontar diferentes formas de regimes de direito à informação, porém, mesmo que ocorram variações, também existem semelhanças consideráveis. As práticas observadas com regularidade fornecem uma compreensão mais ampla sobre alguns padrões comuns na área do direito à informação, e assim podem ser elencados algumas características e princípios sobre esse direito, que serão apresentados de forma mais detalhada nos tópicos seguintes.

\subsection{Princípio da Máxima Divulgação}

O princípio da máxima divulgação está presente de forma explícita na legislação de diversos países e consiste na ampla divulgação das informações. Segundo os Padrões da ONU (2000), os órgãos públicos têm obrigação de revelar informações, e todo cidadão ou cidadã tem o direito de receber informações, entendendo-se por "informações" todos os registros mantidos por órgão público, não importando sua forma de armazenamento.

Os Padrões da ONU são relativos tanto às informações como a seus registros, mas o direito principal faz referência ao acesso à informação. Essa distinção acarreta algumas implicações importantes, pois ter acesso à informação é diferente de ter direito de acesso ao registro ou a algum documento.

Em relação aos órgãos públicos, a maioria dos países não impõe a eles a obrigação de criar informações, mas concedem o direito de acesso à informação de documentos que esses órgãos são obrigados a manter. O acesso à informação de órgãos públicos utilizando tecnologias de informação e comunicação também não está previsto em lei, o que pode dificultar ou atrasar o acesso às informações. Outro ponto a ser observado é se ao fazer um pedido de informação, o requerente precisa indicar em qual documento a informação está, porém, muitos cidadãos nem saberiam dizer o nome do documento relativo à informação que está procurando.

Sobre a definição de Órgãos Públicos, tanto a Convenção de Aarhus (2001) como a Recomendação do CdE os definem num sentido amplo, incluindo governos nacional, regional e outros, além de:

[...] pessoas físicas ou jurídicas na medida em que exercem funções públicas ou autoridade administrativa e conforme o previsto na legislação nacional [...]. Quaisquer outras pessoas físicas ou jurídicas com responsabilidades ou funções públicas, ou prestadoras de serviços públicos. (Recomendação do CdE, 2002).

Porém, nem a Convenção de Aarhus (2001) nem a Recomendação do CdE (2002) incluem os poderes judiciário ou legislativo do governo, distinção também presente em algumas leis nacionais, em parte tendo como base as divisões constitucionais do poder. 
Entretanto, o Princípio II da Recomendação do CdE reconhece, sim, a importância do acesso à informação mantida por esses órgãos públicos.

Já, na África do Sul, por exemplo, até mesmo organizações privadas são obrigadas a divulgar informações que sejam consideradas necessárias à garantia ou defesa de qualquer direito, o que se evidencia no Princípio IV(2) da Declaração Africana (2002) "Todos têm o direito de acesso à informação mantida por entidades privadas que seja necessária para o exercício ou proteção de qualquer direito". Assim, considerando o crescimento da tensão e do apoio às privatizações de empresas e funções que antes eram de obrigações do Estado, esse princípio representa um avanço importante sobre o direito à informação.

Além de definir os responsáveis por fornecer a informação, os padrões internacionais também apontam quem têm o direito de acesso a informação. Segundo os Padrões da ONU, todo membro da população têm o direito de receber informações; o Princípio IV(2) da Declaração Africana também cita "todos"; e o Princípio 4 da Declaração Interamericana coloca "todo indivíduo". Já o Princípio 3 da Recomendação do CdE, além de referenciar a "todos", destaca uma observação. "Este princípio deve-se aplicar sem discriminação de natureza alguma, inclusive de nacionalidade." Porém, sabe-se que algumas leis em determinados países fazem essa discriminação.

Nesse primeiro princípio fica clara necessidade da máxima divulgação das informações; quem são os responsáveis pela divulgação; e quem têm o direito a informação. Tendo conhecimento sobre esse direito e a garantia do referido princípio, é facilitado a todos o elemento básico da literacia midiática, que é o acesso à informação.

\subsection{Princípio da Obrigação de Publicar}

Para assegurar na prática o direito à informação, os órgãos públicos devem ter a obrigação de publicar informações essenciais e não apenas atender aos pedidos de informação. O acesso à informação depende da publicação e divulgação efetiva, voluntária e proativa desses órgãos.

Essa obrigação aparece em diversas declarações internacionais, como os Padrões da ONU:
A liberdade de informação implica que os órgãos públicos publiquem e divulguem amplamente documentos de interesse público significativo, como por exemplo informações operacionais sobre o funcionamento do órgão público e o conteúdo de eventuais decisões ou políticas que afetem a população" (PADRÕES DA ONU, 2000). 
A Declaração Africana (2000), no Princípio IV(2) afirma que "os órgãos públicos deverão ser obrigados, mesmo na ausência de pedido, de publicar ativamente informações importantes de interesse público significativo". E na Recomendação do CdE, princípio XI, também se define que todo órgão público por iniciativa própria e quando apropriado, deve divulgar informações com o objetivo de promover a transparência da administração pública, eficiência administrativa e participação bem informada da população.

A referida participação bem informada da população relaciona-se intimamente às premissas da literacia midiática, que parte do acesso à informação, sua avaliação crítica e, finalmente, ação e participação.

Além das declarações internacionais, muitas leis nacionais também colocam a obrigatoriedade dos órgãos públicos produzirem listas informações públicas, contudo, na maioria das vezes, isso não é cumprido, pois tal atividade depende de outros fatores. Fatores que podem dificultar a produção desses conteúdos são: a quantidade de informação; a falta de recursos humanos ou tecnológicos para buscar e organizar as informações. Porém, essa realidade deve melhorar com uso de tecnologias de informação e comunicação que facilitam a publicação e divulgação.

\subsection{Princípio de um Governo Aberto}

Em muitos países, inclusive no Brasil, existe uma cultura do sigilo no que diz respeito ao governo, suas práticas, números e atitudes, porém, é preciso que os órgãos públicos promovam a abertura dos governos de forma ativa.

Como aponta Mendel:

O direito à informação depende, em última análise, da mudança desta cultura já que é praticamente impossível forçar os servidores públicos a se mostrarem abertos, mesmo com as legislações mais progressistas. Em vez disso, o sucesso, a longo prazo, depende do convencimento dos funcionários públicos de que a abertura não é apenas uma obrigação (indesejada), mas também um direito humano fundamental e essencial para a governança efetiva e apropriada. (Mendel, 2009:34-35).

Uma série de medidas pode ser necessária para transformar a cultura do sigilo em uma cultura de transparência e acesso à informação, assegurando que a população esteja ciente de seu direito de acesso. Essas medidas são apresentadas nos padrões da ONU e Princípio 2 da Commonwealth (1999), que reconhece a necessidade da "promoção de uma cultura de abertura", bem como a Declaração Conjunta (2004) dos mandatários especiais, que cobra do governo "tomar providências ativas para tratar da cultura do sigilo que ainda prevalece no setor público de vários países" e medidas "para promover a ampla conscientização da população quanto à lei de acesso a informação". 
Já o Princípio X da Recomendação do CdE inclui medidas referentes a informar a população e capacitar os servidores para disponibilizar as informações, pois muitas vezes eles não têm conhecimento sobre quais informações dispõem ou até mesmo sobre como localizá-las.

Sobre a gestão de documentos oficiais, ela não é apenas essencial para a efetivação do direito à informação, mas também uma das funções básicas de um governo. Como aponta a Declaração Conjunta dos mandatários especiais (2004): "As autoridades públicas devem ter a obrigação de observar padrões mínimos de gestão de registros. Devem ser implementados sistemas para promover a elevação dos padrões ao longo do tempo." E o Princípio 4 da Commonwealth (1999) também coloca que "os governos devem manter e preservar registros". Já o Princípio X da Recomendação do CdE (2002) cobra dos Estados uma gestão adequada dos registros para facilitar o acesso, e também "regras claras e definidas para a manutenção e destruição de seus documentos".

Além da gestão dos registros e informações, outras ferramentas úteis para combater a cultura do sigilo são a publicação de guias simples e acessíveis explicando como fazer solicitações de informações; estabelecimento de penalidades para quem dificultar o acesso à informação, penalidades que podem ser administrativas, civis, penais ou uma combinação delas, o que está presente na Declaração Conjunta.

Por fim, pode-se citar os meios de comunicação social como potenciais aliados na promoção da cultura de abertura, pois podem auxiliar na ampla divulgação de informações em países com altos níveis de analfabetismo e baixa circulação de jornais. Além disso, vale lembrar que, no Brasil, os canais de televisão são concessões públicas, e devem estar a serviço do interesse público.

Nesse sentido, relaciona-se a questão da literacia midiática por conta da penetrabildiade dos media no cotidiano dos cidadãos, que a todo momento recebem uma grande gama de informações. Se esses meios forem utilizados para a promoção de uma cultura de abertura e transparência, as informações sobre o governo aparecerão em maior quantidade e com melhor qualidade, contribuindo para análise crítica por parte da população e articulação para mudança.

\subsection{Princípio da Abrangência das Exceções}

Como já foi citado anteriormente, as exceções do direito de acesso à informação devem ser claras e não causar nenhum tipo de dano ao interesse público. Porém, a avaliação dessas exceções é bastante complexa, como aponta Mendel:

Por um lado, um sistema de exceções amplo em demasia pode prejudicar seriamente o direito. [...] Por outro lado, é obviamente importante que todos os interesses legítimos de sigilo recebam a devida consideração, do contrário os 
órgãos públicos seriam licitamente obrigados a divulgar informações, mesmo que isso pudesse causar danos desproporcionais. (Mendel, 2009:36).

Essa complexidade é tratada nos padrões internacionais, e no Princípio 3 da Commonwealth (1999), afirma-se que tais exceções devem ser "limitadas" e "restritamente definidas", já os Princípios Interamericanos admitem que as exceções devem ser excepcionais, definidas previamente por lei, e em resposta a "um perigo real e iminente que ameace a segurança nacional das sociedades democráticas" (Princípio 4); e os Padrões da ONU (2002) também exigem que as exceções tenham respaldo legal.

Diversas leis reconhecem diferentes objetos legítimos de exceção. Por exemplo, a recomendação do CdE apresenta uma lista de possíveis justificativas para a restrição do direito a informação, presente no Princípio IV "Possíveis limitações ao acesso a documentos oficiais", apresentada a seguir:

Os Estados-membros podem limitar o direito de acesso a documentos oficiais. As limitações devem ser definidas de forma precisa na lei, serem necessárias em uma sociedade democrática e proporcionais ao objetivo de proteger: i. a segurança e defesa nacionais, e as relações internacionais; ii.a segurança pública; iii.a prevenção, investigação e persecução de atividades criminosas; iv. a privacidade e outros interesses privados legítimos; v. interesses comerciais e outros interesses econômicos, sejam privados ou públicos; vi. a igualdade das partes em relação aos processos judiciais; vii. a natureza; viii. a inspeção, controle e supervisão por parte das autoridades públicas; ix. as políticas econômicas, monetárias e cambiais do Estado; $x$. a confidencialidade das deliberações intra ou interautoridades públicas durante a preparação interna de um tema. (Recomendação do CdE, 2002).

Já os Princípios do Artigo 19 do ICCPR colocam três fazes para avaliar a validade das exceções, o teste tripartite:

- as informações precisam ser relativas a um objetivo legítimo registrado na lei;

- a divulgação precisa ameaçar ou causar danos substanciais a esse objetivo; e

- o dano ao objetivo precisa ser maior do que o interesse público de ter as informações. (ICCPR, 1976).

Vários documentos internacionais apontam a necessidade de risco de dano em contraposição ao interesse público, como os Padrões da ONU, a Recomendação do CdE, e a Convenção e Aarhus. De uma forma geral, as exceções devem ser aplicadas apenas em casos nos quais os danos forem superiores ao interesse público no que diz respeito ao acesso a determinadas informações. 
Saber sobre essas exceções e sobre os fatores que as legitimam é de suma importância para o acesso às informações. Se os cidadãos são bem informados sobre seus direitos e sobre o que pode ser restrito ou não ao conhecimento público, auxilia na análise crítica do por quê determinadas informações não vêm a tona e quais são os mecanismos possíveis para acessar essas informações. Reivindicar o acesso à informação também é uma forma de participar.

\subsection{Princípio dos Procedimentos que Facilitem o Acesso}

De acordo com Mendel (2009), os pedidos de informação devem ser processados com rapidez e justiça, com a possibilidade de um exame independente em caso de recusa. Dessa forma, é preciso que sejam estabelecidos procedimentos claros para o processamento dos pedidos de informação a serem seguidos pelos órgãos responsáveis.

Sobre esse aspecto, os Padrões da ONU (2000) defendem que os órgãos públicos "instaurem sistemas abertos e acessíveis a fim de assegurar o direito da população de receber informações" com "limites de tempo rigorosos para o processamento de pedidos de informação", e quanto ocorrerem recusas, devem ser informados os motivos concretos para o não fornecimento da informação. De acordo com Declaração Conjunta (2004) dos mandatários especiais, esses procedimentos devem ser "simples, rápidos e gratuitos ou de baixo custo". Já a Recomendação do CdE apresenta detalhamento sobre processo, contendo também alguns padrões específicos, como:

- os pedidos devem ser tratados por quaisquer órgãos públicos que detenham as informações, de forma igualitária e com o mínimo de formalidade;

- os solicitantes não devem ter de justificar seus pedidos;

- os pedidos devem ser atendidos prontamente e dentro de limites de tempo definidos;

- deve-se oferecer assistência "na maior medida possível";

- quaisquer recusas de acesso devem ser justificadas; e

- os solicitantes devem receber acesso na forma de sua preferência, seja pela consulta ao registro ou fornecimento de uma cópia (Recomendação da CdE, 2002).

Quando há recusas, muitas leis nacionais permitem que se entre com recurso, mas é preciso que haja um órgão independente e imparcial que avalie esses pedidos, pois na falta desse órgão, não se pode afirmar que o direito à informação dos indivíduos esteja assegurado, e pode haver interferência de outros interesses envolvidos.

Alguns padrões internacionais fazem referência a um órgão de supervisão ou a tribunais para julgar as recusas. O Princípio 5 da Commonwealth e a Declaração Conjunta dos mandatários especiais sugere que as recusas sejam avaliadas por "um órgão independente com plenos poderes para investigar e solucionar tais queixas", já a 
Recomendação do CdE cita um "tribunal comum ou outro órgão independente e imparcial instituído por lei”. E o Princípio IV(2) da Declaração Africana aponta duas possíveis instâncias de apelação, um órgão independente ou a tribunais.

Por fim, o que se deve ter em conta é que mão importa se essa tarefa será atribuída a um órgão já existente ou se será criado um novo órgão para tal função (como uma ouvidoria ou comissão de direito à informação, por exemplo), mas sim que esse órgão seja protegido contra interferência de interesses políticos.

Garantir a facilidade e rapidez dos procedimentos de acesso e também a imparcialidade de órgãos que analisem as recusas de solicitações de informações é imprescindível pra que mais informações estejam disponíveis à população. Assim, de posse de mais informações, tem-se mais subsídios para análises críticas e participação.

\subsection{Princípio dos Custos}

O sexto princípio é o de que as pessoas não podem ser impedidas do acesso à informação por conta dos cultos envolvidos. Como aponta Mendel, a cobrança de taxas é uma questão complexa, pois: "Por um lado, se as taxas forem excessivas, representarão uma barreira ao acesso e, assim, sabotarão o direito. Por outro lado, a oferta de acesso impõe custos aos órgãos públicos, que deveriam ter algum meio de recuperálos." (Mendel, 2009:40).

Sobre os textos internacionais relativos às cobranças, os Padrões da ONU (200), apontam que seu valor "não deve ser elevado a ponto de impedir que haja solicitantes e contradizer o propósito da própria lei”. O Princípio VII da Recomendação do CdE (2002) sugere que a consulta seja gratuita, mas podem haver cobranças eventuais por cópias que não ultrapassem seus custos reais. Já Convenção de Aarhus (2001) é mais detalhada, e no Artigo 4(8) afirma que as autoridades públicas podem aplicar taxas para o fornecimento de informações, mas essas taxas devem ter valor razoável, além disso, essas taxas devem ser informadas em uma tabela, constando se o recebimento da informação está condicionado ao pagamento prévio do valor estabelecido.

De forma geral, há grande variação em relação ao tratamento da questão das taxas relativas ao acesso à informação em diferentes países, porém, deve-se garantir que o acesso á informação não seja barrado pela questão financeira, que a informação não seja tratada como mercadoria, mas sim como um bem público. Esse entendimento é primordial para que a população se sinta no direito sobre tais informações, de acessálas e utilizá-las para defesa e garantia de direitos e deveres. 


\subsection{Princípio das Reuniões Abertas}

De acordo com Mendel (2009), as reuniões de órgãos públicos devem ser abertas ao público. Esse princípio demonstra que a lógica do direito à informação não é aplicável apenas às informações registradas, mas também ao que é tratado nas reuniões de órgãos públicos, às informações transmitidas por registros ou oralmente. Sobre isso, os Padrões da ONU (2000) apontam que: "A lei [sobre direito a informação] deveria estipular a presunção de que todas as reuniões dos órgãos do governo fossem abertas ao público". Como aponto o autor, são poucas as leis de direito à informação que determinam essa abertura.

Em relação às reuniões abertas, seria necessário divulgar à população o direito de participar delas, e tendo acesso a esses espaços, uma possibilidade é utilizar-se dos meios de comunicação disponíveis para divulgar para mais pessoas as informações ali tratadas, como smartphones com acesso às mídias sociais. Dessa forma, além da questão do acesso, estariam contempladas também as outras premissas do processo de literacia midiática, que são a produção de conteúdo e análise crítica das informações disponibilizadas.

\subsection{Princípio da Precedência da Divulgação}

As leis de divulgação devem ter precedência diante de leis de sigilo, assim, "leis que não estejam de acordo com o princípio da máxima divulgação devem ser revisadas ou revogadas" (Mendel, 2009:41)

O direito internacional não define como os Estados devem implementar suas regras, e isso ocorre com as leis relativas ao direito a informação. Quase todos os países possuem leis sobre o sigilo e muitas delas não correspondem aos princípios tratados anteriormente. Assim, cada Estado tem por obrigação criar mecanismos para solucionar tais incongruências.

Sobre essa questão, o Princípio IV(2) da Declaração Africana (2002) aponta que: "[A]s leis de sigilo deverão sofrer as emendas necessárias para cumprir os princípios de liberdade de informação", essa seria uma solução de médio prazo. Uma opção mais rápida seria, como aponta Mendel (2009), determinar que a lei que institui o direito a informação tenha precedência em relação às leis de sigilo. No mesmo sentido, a Declaração Conjunta (2004) dos mandatários especiais afirma que "a lei de acesso a informação deve, no tocante a quaisquer incongruências, prevalecer sobre outras leis".

Dessa forma, garantindo a precedência da divulgação, seriam assegurados o acesso à informação, a possibilidade de análise crítica dessas informações; da utilização das mídias disponíveis para divulgação; e de debate e ação. 


\subsection{Princípio da Proteção aos Denunciantes}

Esse princípio afirma, basicamente, que quando alguém denuncia um crime, essa pessoa precisa ser protegida. Como coloca Mendel:

A proteção é importante para mudar a cultura de sigilo no âmbito do governo e para fomentar um clima de abertura. Proteção semelhante é oferecida em vários países aos indivíduos que revelam informações sobre atos ilícitos: os denunciantes (Mendel, 2009:42).

Como exemplos de textos internacionais, o Princípio IV(2) da Declaração Africana destaca que ninguém deve ser punido por revelar, de boa fé, informações sobre atos ilícitos, ou que prejudiquem a saúde, segurança ou meio ambiente. Os Padrões da ONU afirmam que deve haver proteção contra "quaisquer sanções legais, administrativas ou empregatícias por causa da revelação de informações sobre atos ilícitos" e definem com o ato ilícito "o cometimento de crime ou ato de desonestidade, descumprimento de uma obrigação legal, injustiça, corrupção, ou desonestidade ou falhas graves na administração de um órgão público".

Dessa forma, ao oferecer essa proteção, seria estimulado um maior fluxo de informações para a população, que teria a possibilidade de avaliá-la, discutir sobre o assunto e até mesmo tomar providências iniciadas com essa ação comunicativa, como reivindicações contra corrupção, por exemplo, cumprindo as premissas da literacia midiática.

\section{CONSIDERAÇÕES FINAIS}

No decorrer do artigo, buscou-se relacionar os princípios que caracterizam um regime de direito à informação com as premissas da literaria midática, que passam pelo acesso à informação; análise crítica; e comunicação para uma ação cidadã. Foi possível notar que cada princípio se relaciona a tais etapas, podendo até mesmo contemplar mais de uma delas.

Nota-se também que, se assegurados os princípios tratados no trabalho desenvolvido por Mendel (2009), o Direito à Informação proporciona importantes ganhos à sociedade, bem como o fortalecimento da democracia e o fomento da capacidade dos indivíduos participarem ativamente e cobrarem seus governos, o que se relaciona aos objetos da literacia midiática no que diz respeito a habilitar o cidadão para realizar buscas de informação, analisá-las de forma crítica e participar de maneira engajada para se manifestar, reivindicar defender e garantir direitos e deveres.

Exemplos de participação advinda do uso do direito à informação podem ser relacionados ao acesso e divulgação sobre ações ilícitas e atos de corrupção, que causam indig- 
nação e também reflexão por parte população. A partir do momento em que há o compartilhamento das informações, abre-se espaço para o debate e para a partilha de motivação e vontade de agir para transformar aquela realidade.

O conhecimento sobre as leis que tratam do direito à informação, e mais especificamente do acesso, auxiliam na compreensão de que a informação é um bem público, e deve servir ao interesse público. Sendo assim, é preciso que haja respaldo legal para sua divulgação e facilidade de acesso a qualquer pessoa. Além desse respaldo, seria preciso ainda instruir a população sobre esse direito, pois muitos não sabem que o possuem, e dessa forma, incentivar a busca pela informação, análise e participação.

Por fim, é importante destacar que boas leis não são o bastante para assegurar o direito à informação, porém, as leis são pré condições para que isso ocorra. Reconhecer o direito à informação como um direito humano fundamental, ligado ao direito de liberdade de expressão, garante não apenas poder transmitir informações, mas também buscar, requisitar e receber informações. Fomentar o direito à informação é também contribuir para o processo de literacia midiática, e por fim, para a participação mais consciente e ativa da população.

\section{Notas}

${ }^{1}$ Trabalho apresentado no IV Congresso Internacional Comunicação e Pensamento, realizado de 10 a 12 de abril de 2019 na Universidade de Sevilha, Espanha.

Apoio CAPES (Coordenação de Aperfeiçoamento de Pessoal de Nível Superior), processo 88881.187744/2018-01 e FAPESP (Fundação de Amparo à Pesquisa do Estado de São Paulo) processo 2017/10107-8, Brasil.

\section{Referências}

Andrelo, Roseane \& Bighetti, Wanessa V. F. (2014). Media literacy, memória e eleições - como jovens interpretam o apelo à memória na campanha presidencial de 2014. Comunicação \& Educação. Ano 20. N. 2 - $2^{\circ}$ Sem. 2015. Recuperado de: http://www.revistas.usp.br/comueduc/article/view/86953

Arhus, Convention. (2001). Convention on Access to Information, Public Participation in Decision-Making and Access to Justice in Environmental Matter. Doc. da ONU ECE/CEP/43, adotado na Quarta Conferência Ministerial no processo "Meio ambiente para a Europa", 25 de junho de 1998, com entrada em vigor em 30 de outubro de 2001. 
Bévort, E. \& Bellonil, M.L. Mídiaeducação, conceitos, história e perspectivas. Revista Educação e Sociedade, set/dez. p. 1087. 2009. Recuperado de: http://www.scielo.br/pdf/es/ v30n109/v30n109a08.pdf

Comissão Européia. (2007). Comunicação da Comissão ao Parlamento Europeu, ao Conselho, ao Comité Económico e Social Europeu e ao Comité das Regiões Uma abordagem europeia da literacia mediática no ambiente digital. 2007. Recuperado de: http://eur-lex.europa.eu/legalcontent/PT/TXT/?uri=CELEX:52007DC0833

Commonwalth (1999). Reunião de Ministros da Justiça da Commonwealth. Port of Spain.

Declaração Africana. (2002). 32ª Sessão Ordinária da Comissão Africana sobre Direitos Humanos e dos Povos. 17 a 23 de outubro de 2002, Banjul, Gâmbia. Recuperado de: http://www.achpr.org/english/declarations/declaration_freedom_exp_en.html

Hack, Osvaldo H. (2002). Apresentação. In: Um olhar sobre cidadania. São Paulo: Mackenzie, p. 7. (Coleção Reflexão Acadêmica).

ICCPR, Pacto Internacional de Direitos Civis e Políticos (1976). Resolução da Assembleia Geral da ONU 2200 A (XXI). De 16 de dezembro de 1966, com entrada em vigor em 23 de março de 1976.

Mendel, Toby. (2009). Liberdade de informação: um estudo de direito comparado. Unesco. Recuperado em: http://www.acessoainformacao.gov.br/central-deconteudo/publicacoes/arquivos/liberdade-informacao-estudo-direito-comparado-unesco.pdf

Padrões da ONU (2000). Relatório do Relator Especial, Promotion and protection of the right to freedom of opinion and expression. Doc. da ONU E/ CN.4/2000/63, de 18 janeiro de 2000 , § 44 .

Recomendação, CdE. (2004). Recomendação do Comitê de Ministros aos Estadosmembros sobre o acesso a documentos oficiais. 21 de fevereiro de 2002. Adotada em 6 de dezembro de 2004. Recuperado de: http://www.unhchr.ch/huricane/huricane.nsf/0/9A56F80984C8BD5EC1256F6B005C47F0?opendocument

Tornero, J; Celot, P. \& Varis, T. (2010). Current trends and approaches to media literacy in Europe. Recuperado de: http://ec.europa.eu/avpolicy/media_literacy/studies/index_en.htm 


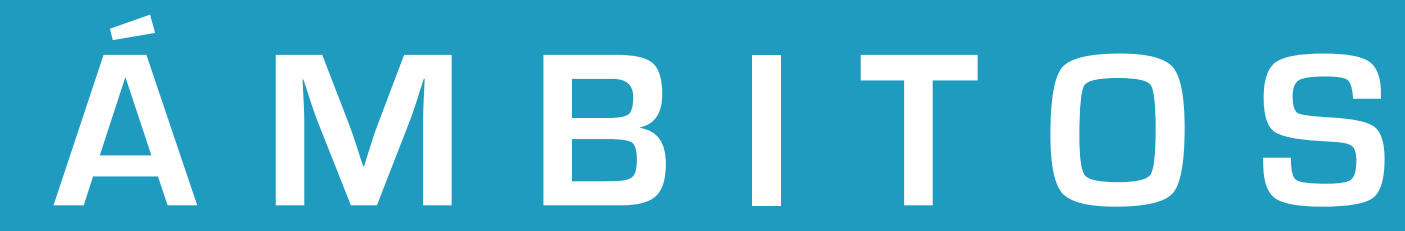

ISSN: 1139-1979 | ISSN digital: 1988-5733 | Depósito Legal: SE-1493-98

Revista Internacional de Comunicación editada por el Grupo de Investigación en Estructura, Historia y Contenidos de la Comunicación(GREHCCO) de la Universidad de Sevilla.

\section{ambitoscomunicacion@us.es}

http://institucional.us.es/ambitos

@RevistaAmbitos 